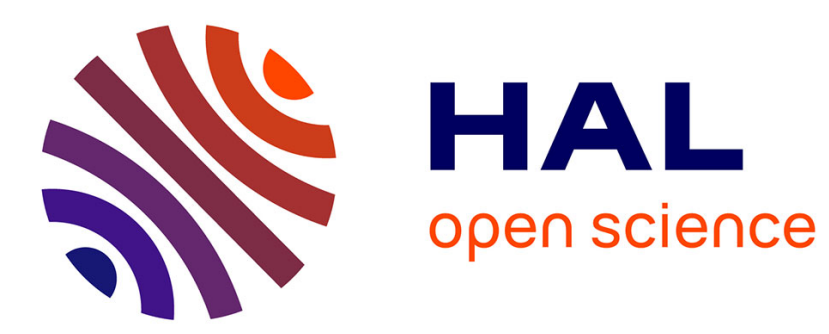

\title{
On-line Coordination in Complex Goal-directed Movements: a Matter of Interactions between Several Loops.
}

Lilian Fautrelle, François Bonnetblanc

\section{- To cite this version:}

Lilian Fautrelle, François Bonnetblanc. On-line Coordination in Complex Goal-directed Movements: a Matter of Interactions between Several Loops.. Brain Research Bulletin, 2012, 89 (1), pp.57-64. 10.1016/j.brainresbull.2012.07.005 . lirmm-00805182

\section{HAL Id: lirmm-00805182 https://hal-lirmm.ccsd.cnrs.fr/lirmm-00805182}

Submitted on 5 Apr 2013

HAL is a multi-disciplinary open access archive for the deposit and dissemination of scientific research documents, whether they are published or not. The documents may come from teaching and research institutions in France or abroad, or from public or private research centers.
L'archive ouverte pluridisciplinaire HAL, est destinée au dépôt et à la diffusion de documents scientifiques de niveau recherche, publiés ou non, émanant des établissements d'enseignement et de recherche français ou étrangers, des laboratoires publics ou privés. 
On-line coordination in complex goal-directed movements: a matter of interactions between several loops.

Lilian Fautrelle ${ }^{2,3}$, François Bonnetblanc ${ }^{1,2,3^{*}}$

1- Université Montpellier 2 - LIRMM - DEMAR Team, CNRS, INRIA, 161 Rue Ada, F-34095 Montpellier Cedex 5, France

2- Université de Bourgogne, Dijon, Campus Universitaire, UFR STAPS, BP 27877, F-21078 Dijon, France

3- INSERM, U-1093, « Cognition, Action, et Plasticité Sensorimotrice » », UFR STAPS, Dijon, F21078, France

*- Corresponding author, François Bonnetblanc:

Fax : +33(0)3 80396702

e-mail: francois.bonnetblanc@u-bourgogne.fr 


\section{Abstract:}

Motor flexibility is the ability to rapidly modify behavior when unexpected perturbations occur. In goal directed movements, this process may be involved during the motor execution itself, by using online motor corrections, or off-line, on a trial-by-trial basis. A consensus has emerged to describe and unify these two dependant processes within the framework of the internal models theory in which the cerebellum is involved in error processing. However, this general framework may be incomplete to describe on-line motor corrections when complex motor coordination is involved in the task. In particular, interaction torques existing between different effectors limit the independence between different controllers that could be considered to control various body parts. In addition, recent findings suggest that different (sub)-cortical loops may be involved during orienting responses to visual stimuli but also during on-line motor corrections following visual perturbations. The way these different loops with different dynamics interact but achieve the same motor goal is an important problem in motor control. The simplest organization may be sequential, as in the well-known stretch reflex. This implies that during on-line corrections, the nervous system may be involved in a distributed fashion and that motor plans and synergies depend both on anatomical and temporal constraints. More particularly, motor plans and synergies may be stored and may differ according to the (sub)-cortical loops involved during the whole on-line correction process. Finally, questions concerning the independence (or not) of these loops remain unanswered. The case of strict independence would mean that between the various corrective loops, (i) error processing and (ii) motor plans/synergies would be different. By contrast, in a situation of dependency, it would probably mean that interactions would link lower (and faster) to upper (and longer) loops by informing these latter of the motor corrections sent by the former, similarly to an efference copy. 


\section{On-line control and the internal models theory}

The concept of internal models has emerged in order to deal with two main problems constantly met within the study of motor activities. The first of these problems concerns the feedback delays needed for information transduction, transmission and processing that greatly limit on-line control, namely the capacity to modify the movement during its own execution. The second concerns the transformation from perceptual to motor coordinates.

Internal models are neural networks that can mimic, simulate and predict dynamic processes external to the brain. They can simulate or predict characteristics of the body and the environment or their inverse (Wolpert et al. 1998a; Kawato 1999). Biologically, they are plastic networks, submitted to learning rules that depend on feedback. There are two types of internal models: the "feedforward models" and the "inverse models". Their functions are respectively: (i) to predict reafferences and cancel biophysical delays in motor corrections and (ii) to predict motor commands according to the represented movement goal (see Desmurget and Grafton 2000, Wolpert and Ghahramani 2000 and Wolpert et al. 2001 for reviews).

Using efference copies, feedforward models allow prediction of sensory consequences and can thus manage to predict the whole behavior of a motor system. The central nervous system can estimate the current and future states of an effector with no delay. For instance, a feedforward model of the arm dynamic predicts the subsequent state (e.g. position and velocity) based on peripheral sensory information and the efference copy of the motor command (see figure 1). Inverse models transform the represented goal into motor coordinates. In this theory, these inverse models are assimilated to "controllers". In other words, they establish a causal relationship that links the predicted consequences of an action to the action itself. This process is used to update feedforward commands and calibrate internal models or representations of the dynamics of our own body or of our physical interaction with the environment (Wolpert and Miall 1996). It is assumed that the cerebellum stores a motor memory in the form of internal models and is a key structure in updating these internal models (Marr 1969; Blomfield and Marr 1970; Kawato et al. 1987; Johansson and Cole 1992; Wolpert and Miall 1996; 
Kawato and Wolpert 1998; Wolpert and Kawato 1998; Wolpert et al. 1998b; Johansson 1998; Imamizu et al. 2000, Ito 2000; Blakemore et al. 2001).

Please insert figure 1 here

Predictive compensation of interaction torques challenges the hypothesis of separate controllers for different effectors in the brain: insights from complex movements with more degrees of freedom.

Generally neuroscientists build motor control schemes that are limited to a single anatomical part of the body. For instance, in most of the literature about reaching, it is specified in substance that a 'forward model of the dynamic of the arm, leg, head, eye, etc' is used. (e.g. Desmurget and Grafton 2000 and many more articles in the field). Within this framework, it is often implicitly assumed that control of the separate anatomical parts of the body, is achieved by independent controllers with distinct internal models.

However, when two or more effectors are linked mechanically and move together, certain interaction torques or forces occur that perturb the movement of each effector. This is true in simple arm reaching movements and even more so in complex movements in which many joints and degrees of freedom are involved. In particular, these torques are critical when both equilibrium constraints and goaldirected movements are combined in the same task such as those we perform in many everyday physical activities.

Based on the kinematics invariance observed in a wide variety of movements and involving various combinations of motor effectors, it has been demonstrated that interaction torques are compensated in a predictive manner (Morasso 1981, Soechting and Lacquaniti 1981, Hollerbach and Flash 1982, Koshland and Hasan 1994, Cooke and Virji-Babul 1995, Koshland et al. 2000), learnt and integrated 
into the control processes (Shadmehr and Mussa-Ivaldi 1994; Wolpert et al. 1995a; Gribble and Ostry 1999; Shadmehr and Moussavi 2000). Thus, interaction torques impose reciprocal dynamic perturbations among the various effectors involved in the whole motor coordination and may continuously perturb the whole movement if they are not anticipated. Internal models are thus supposed to capture these internal dynamics of the body. If interaction forces can be compensated in a predictive manner, this suggests that they are integrated under a common controller. Indeed, the prediction of interaction forces implies predicting the perturbation generated by one effector and transforming it into motor coordinates sent to the other (which is by definition the role of the controller; see figure 1). This kind of motor prediction is a classical and well-known problem in motor control, especially in the field of coordination between posture and movement, when considering anticipatory postural adjusments. Indeed, some initial postural adjustments are supposed to compensate in an anticipatory manner for the upcoming self-perturbation associated with the movement (Belenkii et al. 1967, Massion 1992, Aruin and Latash 1995). This schema of predictive compensation is incompatible with the hypothesis of separate controllers for effectors in the brain but is in line with the results of Kiemel et al. (2008) who demonstrated that multiple movement patterns are possible from a single neural strategy. The sensori-motor transformations required between two effectors which interact mechanically need to share a common pathway to ensure a predictive and reciprocal compensation of interaction torques. By extension, interaction torques could not be compensated in a predictive manner with two independent controllers.

In addition, in the case of separate controllers for various effectors, continuous compensations of interaction torques would induce long delays and limit motor flexibility. Imagine, for instance, a task that requires some correction of the arm movement in an unpredictable manner. The moving arm induces a displacement of the center of mass. This displacement must be compensated to maintain equilibrium and can only be performed after a certain amount of time that represents the transmission delays (afference and efference) added to reprogramming delays. As reprogramming delays are at least 100-120 ms (Pélisson et al. 1986, Prablanc and Martin 1992, Paillard 1996, Pisella et al. 2000, Fautrelle et al. 2010a), motor corrections in postural muscles should appear at least at the same time, 
after the motor corrections sent to the arm have ended so as not to interact (slightly depending on where these latter motor corrections are observed and also on conduction delays). Thus, in the case of a separate control, delays to coordinate movement and equilibrium could be very limitative for motor flexibility. This line of argumentation is illustrated in figure 2 .

Please insert figure 2 here

This hypothesis of delayed 'postural' corrections with respect to arm motor corrections is not clearly verified by experimental data. Indeed, Fautrelle et al. (2010a) recently revealed rapid motor corrections in the upper and lower limbs, with latency responses of less than $100 \mathrm{~ms}$, by contrasting electromyographic activities in perturbed and unperturbed trials. The earliest responses were observed primarily in the anterior section of the deltoïdus anterior (shoulder) and the tibialis anterior (leg) muscles. These findings indicate that visual on-going movement corrections may be accomplished via fast loops at the level of the upper and lower limbs and may not require cortical involvement. In addition, they suggest that when the dynamic of a reaching task is modified, there is no hierarchical processing of upper over lower limb motor corrections and motor flexibility in rapid movements probably involves a complex coordination of the whole body schema. In other words, it suggests that the selection of a more complex dynamic is not detrimental for motor corrections. There is no separated controller between upper and lower limbs in this case. These results are thus important in the understanding of motor correction organization in more complex and ecological movements.

\section{On-line control can also be achieved with very fast loops and in a distributed manner.}

In complex goal-directed movements with a visual double-step target jump, when observed at the muscular level, early movement corrections do not necessarily follow a proximo-distal or lower to 
upper order (Fautrelle et al. 2010a,b, Fautrelle et al. 2011). A first interpretation of this phenomenon would be that distributed muscle activities are separately and independently triggered. Interestingly, this hypothesis is recurrent in the field of motor control and has already been put forward to solve similar problems, especially when questioning the control modes of transport vs. grasping components, with no clear-cut answer (Jeannerod's “Channel hypothesis” 1981, 1984).

However, in our case and as previously mentioned, this suggestion of a separate control of lower vs. upper limb muscle activities is limited by the complex interactional torques that arise and reciprocally influence, in a deleterious fashion, the control of each supposed "sub-movement". In this vein, Gribble and Ostry (1999) demonstrated that in multi-joint movements, central control signals to muscles are adjusted in a predictive manner, to compensate for interactional torques. These results suggest a complex representation of the body schema early in movement planning that seriously weakens the conception of the anatomy-based segmentation in the brain for movement control. Interestingly, this problem does not exist when the eyes are coordinated with the head, due to the huge difference of inertia between the two effectors. Both internal models (controllers) can be distinguished as is illustrated in the vestibulo-ocular reflex (VOR) or during the oculo-manual pursuit. For instance, in this latter case, Scarchilli et al. (1999) demonstrated that an internal model of the arm dynamics may be used to enslave eye to arm movements with separated controllers. By contrast, if a single corrective process is involved, this suggests that the efference copy may commonly integrate a representation of the whole motor sequence to be triggered.

Secondly, it has also been suggested that motor responses observed at different time scales may involve different loops and various processing levels (Paillard 1996, Corneil et al. 2004, Saijo et al. 2005, see Gomi 2008 for a review, Fautrelle et al. 2010a). More specifically, rapid motor responses have been observed during orienting or initiation responses both at the neck and arm level (Corneil et al. 2004, Pruszinski et al. 2010) as well as during motor corrections following visual double-step target jumps, at the eye and arm levels (Gaveau et al. 2005, Saijo et al. 2005 respectively) and very recently both at the upper and lower limb levels (Fautrelle et al. 2010a). 
These studies have demonstrated that humans are sometimes capable of initiating movements towards visual stimuli or correcting them at extremely short latencies, implying the presence of a short-latency neural pathway linking visual input to limb motor output.

\section{Rapid orienting responses}

During orienting responses of the head, Corneil et al. (2004) observed rapid visual responses on neck muscles when express saccades were required. Because of the head's inertia, it was unknown whether express saccades were accompanied by a parallel command to the head. These authors recorded EMG activities from monkey neck muscles and demonstrated that the visual target presentation elicited time-locked lateralized recruitment of neck muscles at extremely short latencies (55-95 ms). They hypothesized that these rapid responses revealed a selective gating of descending command from the superior colliculus to prevent express saccades and to permit recruitment of head orienting synergy. They also concluded that such selective gating facilitated the eye-head coordination by permitting force development of the neck muscles while a decision to commit a gaze shift is being made, optimizing the contribution of the more inertial head to the ensuing gaze shift. In the same vein, Pruszynski et al. (2010) observed stimulus locked responses on human arm muscles, revealing a rapid neural pathway linking visual input to arm motor output. As Corneil et al. (2004) demonstrated that oculomotor structures contribute to 'visual responses' on neck muscles, these authors suggested that these subcortical structures may also target certain arm muscles via a tecto-reticulo-spinal pathway and that similar visual responses should be observed in arm muscles. They found rapid arm muscle activity $(<100 \mathrm{~ms}$ latency) that was time-locked to target appearance and not movement onset. In addition, they observed visual responses in arm muscles only when subjects immediately had to reach towards the target. They concluded that a rapid neural pathway may link the visual input to arm motor response using a common neural mechanism for hastening eye, head and arm movements. Such responses are thought to form part of the visual-grasp reflex that orients the gaze axis (eyes and head) to novel visual stimuli (Hess et al. 1946). They probably reflect rapid processing of visual information in oculomotor structures (Grantyn and Berthoz 1985, Schmolesky et al. 1998, Munoz et al. 2000, Corneil et al. 
2002), including the superior colliculus (Dorris et al. 1997). It was shown that oculomotor structures also target arm muscles via tecto-reticulo-spinal projections (Illert et al. 1978, Werner 1993, Stuphorn et al. 1999).

Interestingly, experimental data demonstrated that these rapid orienting responses may be generated both at the cortical and subcortical levels. Indeed, at the cortical level, it was shown that the ventral and dorsal pre-motor cortex quickly respond to visual stimuli (Rizzolatti et al. 1981, Cisek and Kalaska 2005). More specifically, the ventral pre-motor cortex is the origin of projections that target both the oculomotor and skeletal-motor systems (Billig and Strick 2009). In addition, Cisek and Kalaska (2005) observed neurons in the dorsal pre-motor cortex that respond to visual stimuli with onset latencies as brief as $50 \mathrm{~ms}$. At the subcortical level, the superior colliculus (SC) is known to be involved in orienting responses with saccadic eye movements (Munoz et al. 2000, Sparks 2002), head rotations (Corneil et al. 2002, 2004) and hand-eye coordination (Werner 1993, Lunenburger et al. 2001). It was demonstrated that tecto-reticulo-spinal pathways preferentially targeted proximal arm muscles (Stuphorn et al. 1999) and that a high proportion of neurons exclusively shows an activity related to reaching which was not related to saccadic eye movements.

Altogether, these findings strongly suggest that rapid motor responses inducing the same behavior may be associated with different (sub)-cortical loops. This may be quite similar in motor corrections.

\section{Rapid correcting responses}

Gaveau et al. (2003) have reported very fast motor corrections using eye kinematics, occurring only 50 ms after visual double-step stimulation during saccadic eye movements. These authors suggest that the superior colliculus may be involved in these functional corrective loops.

More recently, when subjects were required to point to a target that randomly and unexpectedly jumped forward to a constant spatial location, Fautrelle et al. (2010) observed rapid motor corrections in the upper and lower limbs, with latency responses of less than $100 \mathrm{~ms}$. These motor corrections were revealed by contrasting electromyographic activities in perturbed and unperturbed trials. The 
earliest responses were primarily observed in the anterior section of the deltoïdus (shoulder) and the tibialis anterior (leg) muscles, suggesting that visual on-going movement corrections may be accomplished via fast loops at the level of the upper and lower limbs and may not require cortical involvement. Indeed, motor corrections following the target jump may be triggered by lower level loops involving few synaptic relays. In contrast to the slow signal processing within the cortex and especially slow conduction velocity $\left(\sim 1-2 \mathrm{~m} . \mathrm{s}^{-1}\right.$, Buillier et al 1988), some studies have shown quicker adjustments in cat limbs during goal-directed movements, suggesting that sub-cortical structures are involved in these rapid motor corrections (Alstermark et al. 1987, Pettersson et al. 1997, Pettersson and Perfiliev 2002). These authors suggest that visual control is exerted via ponto-cerebellar pathways. In a patient with a complete agenesis of the corpus callosum, Day and Brown (2001) observed similar adjustments in latency, irrespective of the target jump direction or the hand used, once again suggesting that visual control was not necessarily cortical.

Finally, working with reaching movements of the arm, it has been shown that sudden visual background displacement induces motor corrections (Priout et al. 2002). Saijo et al. (2005) have shown that these motor corrections can be observed at the arm level with 100 ms EMG latencies. These quick responses seem to be functional, as subjects were unable to cancel the initial correction even when instructed to move to an opposite direction. They suggested that these responses were reflexive and served to stabilize the hand similarly to reflexive eye movements involved in stabilizing the retinal image. Bresciani et al. (2002) have suggested similar reflexive processes after vestibular stimulation as for the VOR. In addition, they argued that this mechanism regulated arm movement along with voluntary movement control.

Although we cannot draw unequivocal conclusions on the nature of the loops involved in the motor corrections presented here, their short latencies suggest the involment of lower and subcortical levels. In these types of corrections, parts of the networks identified by positron emission tomography (PET) functional neuroanatomy are known to involve the posterior parietal cortex and the cerebellum 
(Desmurget et al. 1999, 2001). These findings suggest that there are potential rapid cortical or subcortico-spinal corrective loops that remain to be identified in the rapid motor correction process.

\section{On-line control is achieved by means of different loops: A multi-level motor correction process.}

In the light of some of these results, Gomi (2008) has postulated that multiple on-line visually guided correction mechanisms exist and implicitly govern reaching movements. He distinguished a high level control (voluntary control) that would provide greater flexibility in detriment to a greater computational load and conscious effort from a lower level control. By contrast, the hallmark of this reflexive control would be higher reaction speed and automaticity, but the main drawback would be a limited flexibility that could be compensated by higher processes. This view of a multi-level processing in motor corrections is also supported by studies that demonstrated different delays in motor corrections despite an identical reaching task. For instance, Veerman et al. (2008) demonstrated that the latency for correcting a movement depends on the visual attribute that defines the target. More specifically, they observed that responses for the attributes of color, form, and texture were $50 \mathrm{~ms}$ slower than for those of orientation, luminance and size. They hypothesized that different processing pathways were involved, although possible variations in the transduction delays cannot be excluded. In the same vein, Fautrelle et al. (2011) observed that when speed-accuracy trade-off was unexpectedly modified during a pointing movement, hand velocity was monitored on-line in spite of the fact that terminal variability was held constant across the various target size conditions. They suggested that in this task, intermediate representations of the hand displacement were involved, thus suggesting a higher mode of on-line control. Previously, for arm reaching movement, Desmurget et al. (1997) demonstrated that unconstrained and compliant movements involved different planning strategies. In their experiment, they compared reaching movements with the same spatial goal made with either the index fingertip (unconstrained) or using an "intermediate tool" (e.g. hand-held cursor, pen, manipulanda, etc) which involved a motion constrained by external contact (compliant). They observed different kinematics of the endpoint for the two types of movements and concluded that 
different planning strategies could be involved in spite of the fact that the task and the motor goal look the same. More particularly, in an interesting investigation of the speed-accuracy trade-off in a PET parametric study, Winstein et al. (1997) observed that as the index of difficulty of a task decreased, significant increases in regional cerebral blood flow (rCBF) were evident in the anterior cerebellum, left middle occipital gyrus, and right ventral premotor area. Functionally, these areas were associated with pointing conditions in which the demands for motor execution were high and precise trajectory planning was minimal. By contrast, as the pointing task difficulty (ID) increased, rCBF increased in areas associated with the planning of more complex movements requiring greater visuomotor processing. In particular, when more precise targeting was required, a cortical-subcortical loop composed of the controlateral motor cortex, intraparietal sulcus and caudate was activated. As a whole, this study revealed that two different networks were involved when the required precision varied, in spite of the fact that the behavioral task remained the same. In Fautrelle et al.'s (2011) experiment as the target size could be drastically modified, a constraint may be that the CNS has to switch from one planning strategy to another or from one network to the other. When the results of the two previously mentioned studies by Fautrelle et al. (2010 and 2011) were compared, we noted that movement times were very short $(<600 \mathrm{~ms})$ in both studies. However, correction times and corrective processes were very different. This indicates that flexibility may yield quite similar motor behaviors, based nonetheless on different neural processes. Higher to lower processes may be involved in triggering on-line motor corrections.

The multi-level processing of motor corrections proposed by Gomi (2008) also challenges our understanding of motor coordination in general, as multiple representations of the body schema and/or motor actions may be involved in various substrata and loops. The question of how these loops remain coordinated is not yet answered. More specifically, the way cortical and subcortical structures may interact is of particular interest. For instance, Hoffmann et al. (2009) investigated the role of neurons in the medial temporal area and the medial superior temporal area in perception and actions, demonstrating their connections with (sub-)cortical structures involved in the control of eye and arm movements. In the same vein, neurons of the dorsal Superior Colliculus have been shown to display 
persistent levels of low-frequency activity in advance of target presentation (Glimcher and Sparks 1992, Basso and Wurtz 1997, Dorris and Munoz 1998). In his seminal model, Gomi (2008) has suggested the possibility for a top-down influence of higher cognitive modes towards the lower ones. For instance, some a priori knowledge about the task constraints may modulate or inhibit lower modes of on-line control and prevent the execution of inappropriate reflexive responses.

Altogether, this suggests a classical scheme often observed in motor control, for instance in the socalled "strech-reflex" in which several corrective loops are embedded in a sequential and parallel manner starting with the more rapid and stereotyped corrections (M1 response) and finishing with the final trans-cortical loop that allows terminal adjustments (M3 response) (Petersen et al. 1998). In this vein, Kurtzer et al. (2008) and Pruszynski et al. (2011a,b) demonstrated that the human long-latency reflex is not a single functional response, but rather reflects the output of two functionally independent processes that overlap in time and sum linearly. The first of these functional components shares an important attribute of the short-latency reflex (i.e., automatic gain scaling, sensitivity to background load), and the other shares a defining feature of voluntary control (i.e., task dependency, sensitivity to goal target position). These studies further showed that the task-dependent component of long-latency activity reflected a feedback control process rather than the simplest triggered reaction to a mechanical stimulus. More specifically, Kurtzer et al. (2008) demonstrated that long-latency reflexes possess an internal model of limb dynamics. By directly recording the neuronal activities, Pruszynski et al. (2011b) confirmed this observation and demonstrated that transcortical processing through M1 permits feedback responses to counter unexpected perturbation of the arm. This model may apply to complex coordinations involved in on-line visuo-motor corrections, assuming that long latency motor corrections may be engaged to shape final corrections and smooth dynamical interactions between loops. However, some points should be kept in mind that prevent a direct analogy with the stretchreflex. These should be considered for future discussions. During large visuo-motor corrections, some substantial levels of overlap may be suspected between loops and the displacement of each effector may be increased. Both may induce powerful interaction torques that may be compensated by large terminal motor corrections. Paradoxically, these latter should be critical for on-line control. 
Furthermore, it is important to note in Kurtzer et al. and Pruszynski et al.'s interpretations a persistent modular approach: an internal model of the dynamic limited to the arm was still assumed with no particular reasons for this anatomical delineation. Once again, this modular approach is a presupposition that may not integrate the very physiological aspect of motor coordination. Finally, this parallel architecture limits top-down influences and suggests that higher levels have a limited impact on lower levels. This approach is illustrated in figure 3a. This parallel and sequential organization may be observed in the multi-level on-line corrections model. This simple organization would not need any articulation between the lower and higher loops that could be independent. However, in the framework of a complex motor coordination, several loops may also need several motor maps, especially at the sub-cortical level.

By contrast, another traditional viewpoint in motor control pleads in favor of a hierarchical control. In this particular scheme, sensori-motor control may occur on many different levels and different time scales. However, in this case, lower levels directly interact with the musculoskeletal system and higher levels interact with an augmented plant including the musculoskeletal system and the lower levels. In consequence, to allow this hierarchical control, lower levels have to perform some transformations towards higher levels operating on more abstract movement representations (Sherrington 1906, Bernstein 1996, Loeb et al. 1999, Kalaska et al. 1998, Todorov et al. 2005). These transformations are nevertheless not well understood. In other words, lower levels could not solve a specific sub-task but should instead perform an instantaneous feedback transformation that could admit higher levels to continuously control lower levels output without every detail about the motor plant. This optimized dimensionality reduction achieved by lower levels should admit the brain to monitor a small number of task parameters instead of the full states and map them into motor synergies (Todorov et al. 2005). It supposes that in this model, a set of high-level parameters has to be specified. For instance, applied to reaching movements, this approach revealed a benefit of including velocity as a high-level parameter, even though the cost and the error are computed as a function of position (Todorov et al. 2005). Interestingly, in line with this theoretical hypothesis, Fautrelle et al. (2011) observed that when the accuracy was unexpectedly changed, subjects monitor endpoint velocity (rather than the hand 
position in space) to control the on-going pointing movement. This may reveal a "higher level strategy" to complete the task and may illustrate a hierarchy between different motor strategies involved in pointing movements. However, in this approach the choice of the appropriate high-level parameters together with the potential function used to shape their internal dynamics is a key question and an important limitation with respect to underlying physiological constraints. In particular, it does not easily cope with the existence of many different motor pathways and rapid motor responses with low computational costs, but different schemes could be involved during rapid motor corrections (Gomi 2008). This second approach is illustrated in figure 3b.

Please insert figure 3 here

To sum-up there is no clear-cut answer about the potential architecture involved in on-line coordinations. When rapid motor corrections are required several loops may be involved. In consequence, motor corrections and motor synergies may depend on the anatomical substratum involved which is itself linked to the temporal constraints of the correction (ie biophysical delays). A sequential organization with several independent loops may be involved. The most rapid motor corrections may be similarly triggered by an orienting response that involves basic and rough synergies. For later corrections, the process may be more complex and involve higher cortical loops with more elaborate motor synergies. In case of strict independence, which is the simplest case, it has been previously suggested that interaction torques arising from the successive motor corrections may influence and perturb the subsequent ones. Consequently, to be efficient, these corrections must terminate with late corrections that compensate for previous bias associated with the preceding nonperfect corrections. Each of the various motor correction processes should be clearly separated with a minimum of overlaps. 
By contrast, we could speculate that these various corrective loops are not independent. In this case, once a corrective process is engaged, along with its own motor sequence, it also sends an efference copy to the next loop either directly or indirectly via the cerebellum and allows prediction of the consequences of the previous corrective loops. This system would probably be more efficient. However, neurophysiological evidence for such a bottom-up cascade of linked efference copies is currently lacking.

\section{Conclusions.}

On-line coordination involves the coordination of several loops at once: a complex representation of the body schema is involved (distributed responses at different levels, various loci and substrata) that may need the (sequential) organization of several loops. How is this sequential organization achieved and how are these loops with various latencies embedded together remain open questions and require further investigation. Early stereotyped corrections may not be deleterious for on-line corrections and could be refined later by higher order loops. More generally, reciprocal interaction of lower and higher processes is still the hallmark of motor control and an unsolved problem. Many different routes may be involved to generate the same goal-directed behavior.

Acknowledgments: We would like to thank both reviewers for their stimulating and precise comments about the present work. 


\section{References}

Alstermark B, Górska T, Lundberg A, Pettersson LG, Walkowska M (1987) Effect of different spinal cord lesions on visually guided switching of target-reaching in cats. Neurosci Res. 5(1):63-7.

Aruin AS, Latash ML (1995) The role of motor action in anticipatory postural adjustments studied with self-induced and externally triggered perturbations. Exp Brain Res. 106(2):291-300.

Basso MA, Wurtz RH (1997) Modulation of neuronal activity by target uncertainty.

Nature. 389(6646):66-9.

Belenkii YY, Gurfinkel V, Paltsev YI (1967) Element of control of voluntary movements.

Biofizika 12:135-141.

Bernstein N (1996) Dexterity and its development. In: Latash M, Turvey M, editors. Dexterity and its development. Lawrence Erlbaum 1996.

Blakemore SJ, Frith CD, Wolpert DM (2001) The cerebellum is involved in predicting the sensory consequences of action. Neuroreport. 12(9):1879-84.

Billig I, Strick PL (2009) Anatomical evidence for overlap of oculomotor and skeletomotor control systems in the cerebral cortex. Soc. Neurosci. Abstr., 851.3.

Blomfield S, Marr D (1970) How the cerebellum may be used. Nature19;227(5264):1224-8.

Bresciani JP, Blouin J, Popov K, Bourdin C, Sarlegna F, Vercher JL, Gauthier GM (2002) Galvanic vestibular stimulation in humans produces online arm movement deviations when reaching towards memorized visual targets. Neurosci Lett 18;318(1):34-8.

Bullier J, McCourt ME, Henry GH (1988) Physiological studies on the feedback connection to the striate cortex from cortical areas 18 and 19 of the cat. Exp Brain Res 70:90-98.

Cisek P, Kalaska JF (2005) Neural correlates of reaching decisions in dorsal premotor cortex: specification of multiple direction choices and final selection of action. Neuron. 3;45(5):801-14. 
Cooke JD, Virji-Babul N (1995) Reprogramming of muscle activation patterns at the wrist in compensation for elbow reaction torques during planar two-joint arm movements. Exp Brain Res. 106: $177-180$.

Corneil BD, Olivier E, Munoz DP (2002) Neck muscle responses to stimulation of monkey superior colliculus. II. Gaze shift initiation and volitional head movements. J Neurophysiol. 88(4):2000-18.

Corneil BD, Olivier E, Munoz DP (2004) Visual responses on neck muscles reveal selective gating that prevents express saccades. Neuron 42:831-841.

Day BL, Brown P (2001) Evidence for subcortical involvement in the visual control of human reaching. Brain. 2001 Sep;124(Pt 9):1832-40.

Desmurget M, Jordan M, Prablanc C, Jeannerod M (1997) Constrained and unconstrained movements involve different control strategies. J Neurophysiol. 77(3):1644-50.

Desmurget M, Grafton S (2000) Forward modeling allows feedback control for fast reaching movements. Trends Cogn Sci 4: 423-431.

Desmurget M, Epstein CM, Turner RS, Prablanc C, Alexander GE, Grafton ST (2001)

Role of the posterior parietal cortex in updating reaching movements to a visual target. Nat Neurosci. 1999 Jun;2(6):563-7.

Dorris MC, Paré M, Munoz DP (1997) Neuronal activity in monkey superior colliculus related to the initiation of saccadic eye movements. J Neurosci. 17(21):8566-79.

Dorris MC, Munoz DP (1998) Saccadic probability influences motor preparation signals and time to saccadic initiation. J Neurosci. 1;18(17):7015-26.

Fautrelle L, Prablanc C, Berret B, Ballay Y, Bonnetblanc F (2010a) Pointing to double-step visual stimuli from a standing position: very short latency (express) corrections are observed in upper and lower limbs and may not require cortical involvement. Neuroscience. 25;169(2):697-705.

Fautrelle L, Ballay Y, Bonnetblanc F (2010b) Muscular synergies during motor corrections: investigation of the latencies of muscle activities. Behav Brain Res 25;214(2):428-36. 
Fautrelle L, Barbieri G, Ballay Y, Bonnetblanc F (2011) Pointing to double-step visual stimuli from a standing position: motor corrections when the speed-accuracy trade-off is unexpectedly modified inflight. A breakdown of the perception-action coupling. Neuroscience. 194:124-35.

Gaveau V, Martin O, Prablanc C, Pélisson D, Urquizar C, Desmurget M (2003) On-line modification of saccadic eye movements by retinal signals. Neuroreport. 2003 May 6;14(6):875-8.

Gaveau V, Alahyane N, Salemme R, Desmurget M. (2005) Self-generated saccades do not modify the gain of adapted reactive saccades. Exp Brain Res. 162(4):526-31.

Glimcher PW, Sparks DL (1992) Movement selection in advance of action in the superior colliculus. Nature. 6;355(6360):542-5.

Gomi H (2008) Implicit online corrections of reaching movements.

Curr Opin Neurobiol. 18(6):558-564.

Grantyn A, Berthoz A (1985) Burst activity of identified tecto-reticulo-spinal neurons in the alert cat. Exp Brain Res. 57(2):417-21.

Gribble PL, Ostry DJ (1999) Compensation for interaction torques during single- and multijoint limb movement. J Neurophysiol 82: 2310-2326

Hess, W., Burgi, S. \& Bucher, V. (1946) Motor function of tectal and tegmental area. Monatsschr. Psychiatr. Neurol., 112, 1-52.

Hoffmann KP, Bremmer F, Distler C (2009) Visual response properties of neurons in cortical areas MT and MST projecting to the dorsolateral pontine nucleus or the nucleus of the optic tract in macaque monkeys. Eur J Neurosci. 29(2):411-23.

Hollerbach JM, Flash T (1982) Dynamic interactions between limb segments during planar arm movement. Biol Cybern. 44: 67-77.

Illert M, Lundberg A, Padel Y, Tanaka R. (1978) Integration in descending motor pathways controlling the forelimb in the cat. 5. Properties of and monosynaptic excitatory convergence on C3-C4 propriospinal neurones. Exp Brain Res. 15;33(1):101-30. 
Imamizu H, Miyauchi S, Tamada T, Sasaki Y, Takino R, Pütz B, Yoshioka T, Kawato M (2000) Human cerebellar activity reflecting an acquired internal model of a new tool. Nature. $13 ; 403(6766): 192-5$.

Ito M (2000) Neurobiology: internal model visualized. Nature. 13;403(6766):153-4.

Jeannerod M (1981) Intersegmental coordination during reaching at natural visual objects. In: Long J, Baddeley A (eds) Attention and performance IX. Erlbaum, Hillsdale, NJ, pp 153-169.

Jeannerod M (1984) The timing of natural prehension movements. J Mot Behav 16;235-254.

Johansson RS, Cole KJ (1992) Sensory-motor coordination during grasping and manipulative actions. Curr Opin Neurobiol. 2(6):815-23.

Johansson RS (1998) Sensory input and control of grip.

Novartis Found Symp. 218:45-59; discussion 59-63. Review.

Kalaska J, Sergio L, Cisek P (1998) Cortical control of whole-arm motor tasks. In: Glickstein, M., editor. Sensory guidance of movement: Novartis Foundation Symposium. Chichester, UK: John Wiley and Sons; 1998.

Kawato M, Furukawa K, Suzuki R (1987) A hierarchical neural-network model for control and learning of voluntary movement. Biol Cybern. 57(3):169-85.

Kawato M, Wolpert D (1998) Internal models for motor control. Novartis Found Symp. 218:291-304; discussion 304-7. Review.

Kawato M (1999) Internal models for motor control and trajectory planning. Curr Opin Neurobiol 9:718-27.

Kiemel T, Elahi AJ, Jeka JJ (2008) Identification of the plant for upright stance in humans: multiple movement patterns from a single neural strategy. J Neurophysiol. 100(6):3394-406.

Koshland GF, Hasan Z (1994) Selection of muscles for initiation of planar, three-joint arm movements with different final orientations of the hand. Exp Brain Res. 98: 157-162. 
Koshland GF, Galloway JC, Nevoret-Bell CJ (2000) Control of the wrist in three-joint arm movements to multiple directions in the horizontal plane. J Neurophysiol 83: 3188-3195.

Kurtzer IL, Pruszynski JA, Scott SH (2008) Long-latency reflexes of the human arm reflect an internal model of limb dynamics. Curr Biol. 18(6):449-53.

Loeb G, Brown I, Cheng E (1999) A hierarchical foundation for models of sensorimotor control. Exp Brain Res 126(1):1-18.

Lünenburger L, Kleiser R, Stuphorn V, Miller LE, Hoffmann KP (2001) A possible role of the superior colliculus in eye-hand coordination. Prog Brain Res. 134:109-25.

Marr D (1969) A theory of cerebellar cortex. J Physiol. 202(2):437-70.

Massion J (1992) Movement, posture and equilibrium: interaction and coordination.

Prog Neurobiol. 38(1):35-56. Review.

Morasso PG (1981) Spatial control of arm movements. Exp Brain Res. 42: 223-227.

Munoz DP, Dorris MC, Paré M, Everling S (2000) On your mark, get set: brainstem circuitry underlying saccadic initiation. Can J Physiol Pharmacol. 78(11):934-44.

Nijhawan R (2008) Visual prediction: psychophysics and neurophysiology of compensation for time delays. Behav Brain Sci. 31(2):179-98.

Paillard J (1996) Fast and slow feedback loops for the visual correction of spatial errors in a pointing task: a reappraisal. Can J Physiol Pharmacol. 74:401-17.

Pélisson D, Prablanc C, Goodale MA, Jeannerod M (1986) Visual control of reaching movements without vision of the limb. II. Evidence of fast unconscious processes correcting the trajectory of the hand to the final position of a double step stimulus. Exp. Brain Res. 62, 303-311.

Petersen N, Christensen LO, Morita H, Sinkjaer T, Nielsen J (1988) Evidence that transcortical pathway contributes to stretch reflexes in the tibialis anterior muscle in man. J Physiol. 1;512:267-76. 
Pettersson LG, Lundberg A, Alstermark B, Isa T, Tantisira B (1997)Effect of spinal cord lesions on forelimb target-reaching and on visually guided switching of target-reaching in the cat. Neurosci Res. 29(3):241-56.

Pettersson LG, Perfiliev S (2002) Descending pathways controlling visually guided updating of reaching in cats. Eur J Neurosci. 16(7):1349-60.

Pisella L, Gréa H, Tilikete C, Vighetto A, Desmurget M, Rode G, Boisson D, Rossetti Y (2000) An 'automatic pilot' for the hand in human posterior parietal cortex: toward reinterpreting optic ataxia. Nat Neurosci. 3(7):729-36.

Prablanc, C. \& Martin, O (1992) Automatic control during hand reaching at undetected twodimensional target displacements. J. Neurophysiol. 67:455-469.

Pruszynski JA, King GL, Boisse L, Scott SH, Flanagan JR, Munoz DP (2010) Stimulus-locked responses on human arm muscles reveal a rapid neural pathway linking visual input to arm motor output. Eur J Neurosci. 32(6):1049-57.

Priout P, Guédon O, Proteau L, Gauthier GM (2002) [Targets of the memorized position and visual contexts]. Can J Exp Psychol. 2002 Dec;56(4):253-62.

Pruszynski JA, Kurtzer I, Scott SH. (2011a) The long-latency reflex is composed of at least two functionally independent processes. J Neurophysiol. 106(1):449-59.

Pruszynski JA, Kurtzer I, Nashed JY, Omrani M, Brouwer B, Scott SH (2011b) Primary motor cortex underlies multi-joint integration for fast feedback control. Nature. 478(7369):387-90.

Rizzolatti G, Scandolara C, Matelli M, Gentilucci M (1981) Afferent properties of periarcuate neurons in macaque monkeys. II. Visual responses. Behav Brain Res. 2(2):147-63.

Saijo N, Murakami I, Nishida S, Gomi H (2005) Large-field motion directly induces an involuntary rapid manual following response. J Neurosci. 25(20):4941-4951.

Scarchilli K, Vercher JL, Gauthier GM, Cole J (1999) Does the oculo-manual co-ordination control system use an internal model of the arm dynamics? Neurosci Lett. 265(2):139-42. 
Schmolesky MT, Wang Y, Hanes DP, Thompson KG, Leutgeb S, Schall JD, Leventhal AG(1998) Signal timing across the macaque visual system. J Neurophysiol. 79(6):3272-8.

Shadmehr R, Mussa-Ivaldi FA (1994) Adaptive representation of dynamics during learning of a motor task. J Neurosci 14: 3208-3224.

Shadmehr R, Moussavi ZM (2000) Spatial generalization from learning dynamics of reaching movements. J Neurosci 20: 7807-7815.

Sherrington C (1906) The integrative action of the nervous system.

New Haven: Yale University Press.

Soechting JF, Lacquaniti F (1981) Invariant characteristicsof a pointing movement in man. J Neurosci $1: 710-720$.

Sparks DL (2002) The brainstem control of saccadic eye movements. Nat Rev Neurosci. 3(12):952-64.

Stuphorn V, Hoffmann KP, Miller LE (1999) Correlation of primate superior colliculus and reticular formation discharge with proximal limb muscle activity. J Neurophysiol. 81(4):1978-82.

Todorov E, Li W, Pan X (2005) From task parameters to motor synergies: A hierarchical framework for approximately-optimal control of redundant manipulators. J Robot Syst. 22(11):691-710.

Veerman MM, Brenner E, Smeets JB (2008) The latency for correcting a movement depends on the visual attribute that defines the target. Exp Brain Res. (2):219-28.

Werner W (1993) Neurons in the primate superior colliculus are active before and during arm movements to visual targets. Eur J Neurosci. 1;5(4):335-40.

Winstein CJ, Grafton ST, Pohl PS (1997) Motor task difficulty and brain activity: investigation of goal-directed reciprocal aiming using positron emission tomography. J Neurophysiol. 77(3):1581-94.

Wolpert DM, Ghahramani Z, and Jordan MI. (1995) An internal model for sensorimotor integration. Science 269: 1880-1882 
Wolpert DM, Miall RC (1996) Forward Models for Physiological Motor Control.

Neural Netw. 9(8):1265-1279.

Wolpert DM, Kawato M (1998) Multiple paired forward and inverse models for motor control.

Neural Netw 7-8: 1317-1329.

Wolpert DM, Miall RC, Kawato M (1998b) Internal models in the cerebellum.

Trends Cogn Sci 2: 313-321.

Wolpert DM, Ghahramani Z (2000) Computational principles of movement neuroscience. Nat Neurosci 3 Suppl: 1212-7.

Wolpert DM, Ghahramani Z, Flanagan JR (2001) Perspectives and problems in motor learning. Trends Cogn Sci 5:487-494. 


\section{Figures Captions.}

Figure 1. Schematic control in the Internal models theory. To control an effector within a given environment, a goal is determined based on perceptual information. This goal generates the motor commands (inverse transformation) that integrate the dynamic properties of the effector (inverse model or controller) in order to minimize the output errors. The feedback cumulates a certain amount of delay due to transduction, transmission and processing. If this delay is not compensated for, the actual position of the effector is erroneous. To solve this problem, the brain combines the efference copy (derived from the motor command) and the delayed sensory feedbacks to produce a correct estimation of the current and actual position of the effector. This estimation admits an on-line correction of the motor act. Adapted from (Kawato and Wolpert 1998, Kawato 1999, Desmurget and Grafton 2000).

Figure 2. Continuous compensation of interaction torques limits motor flexibility. According to the dual control hypothesis, equilibrium and movement control do not share a common controller. They are submitted to two distinct motor commands. In complex multijoint movements, because of interaction torques, unpredicted perturbations occur both at the movement and equilibrium levels. These reciprocal and continuous perturbations generate important delays and errors in motor corrections which greatly limit motor flexibility.

Figure 3. Two hypothetical designs for a multi-level model of on-line correction processes. a) Reflexlike independent and parallel motor corrections. In this approach, motor corrections are sent from independent and parallel loops. The output is the sum of different motor commands. Final (longer) corrections are critical to shape the terminal control and to reach the goal. Higher levels have no or a limited influence on lower levels (dotted line). Inspired from Petersen et al. (1988), Kurtzer et al. (2008) and Pruszynski et al. (2011a,b). b) Hierarchical dependent motor corrections. In this approach, single error detection serves to feed all the processing levels. Lower levels interact directly with the musculoskeletal system and higher levels interact with an augmented plant including the musculoskeletal system and the lower system. To allow this hierarchical control, lower levels have to perform some transformation towards higher levels operating on more abstract movement representations. These transformations are not well understood. This model is also limited by a higher computing cost and its physiological relevance (single motor output). Inspired from Sherrington (1906), Bernstein (1996), Loeb et al. (1999), Kalaska et al. (1998) and Todorov et al. (2005). 